\title{
Leukoencephalopathy-thalamus and brainstem anomalies-high lactate syndrome
}

INSERM

\section{Source}

INSERM. (1999). Orphanet: an online rare disease and orphan drug data base. Leukoencephalopathy-thalamus and brainstem anomalies-high lactate syndrome. ORPHA:314051

Leukoencephalopathy-thalamus and brainstem anomalies-high lactate (LTBL) syndrome is a rare, genetic neurological disorder defined by early-onset of neurologic symptoms, biphasic clinical course, unique MRI features (incl. extensive, symmetrical, deep white matter abnormalities), and increased lactate in body fluids. The severe form is characterized by delayed psychomotor development, seizures, early-onset hypotonia, and persistently increased lactate levels. The mild form usually presents with irritability, psychomotor regression after six months of age, and temporary high lactate levels, with overall clinical improvement from the second year onward. 